\title{
Google and Segmentation of the Islamic Finance Body of Knowledge
}

\author{
Mohamed Hamour(1), Saad eldin Mansour Mohammed(2)
}

\begin{abstract}
The study sets out to make evident the existences of segmentation of the Islamic finance body of knowledge (BOK). The segmentation results from the combination of dependency of Islamic finance researchers on google and using Islamic finance terms (IFTs) as search keywords. The study defines Islamic finance terminology as the Arabic/Islamic terms unique to Islamic finance literature written in English, e.g. Shariah. A distinctive feature of Islamic finance terms is that a single term can have many spelling variations. Firstly, to validate the presence of BOK segmentation, we investigated spelling variation among IFTs through a variation analysis among a sample of chosen terms. Secondly, we established the dependency of producers and users of Islamic finance literature on online resources and especially Google and Google Scholar using a survey. Lastly, we observed segmentation in the BOK by examining the absence of search results that overlap for IFTs and their variations. The spelling variations among our samples ranged from zero to eight with an average of (4.8) spelling variations per IFT. The dependency rate on online resources among our respondents was (99\%) on Google, while Google Scholar scored (98\%). The search results' analysis yielded zero overlaps between the search results confirming the actuality of segmentation.
\end{abstract}

Keywords: Segmentation, Islamic Finance Terms, Google, Body of Knowledge, Spelling Variation.

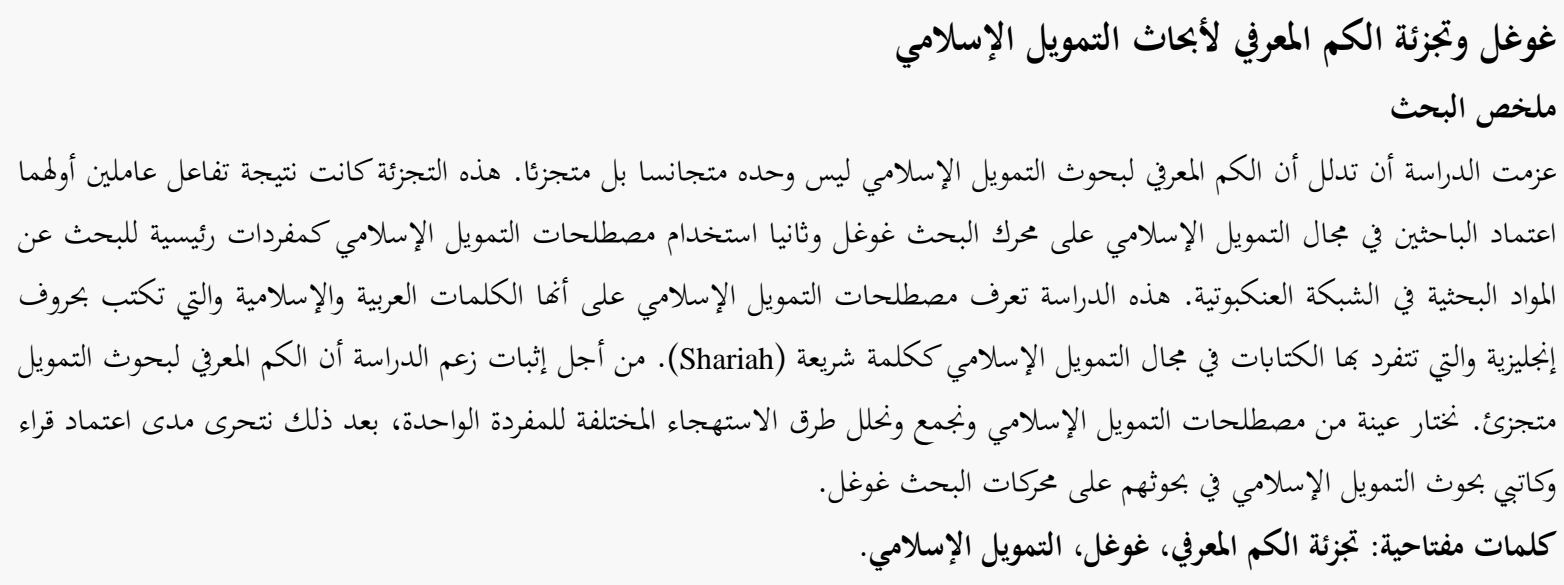

(1) PhD Student, International Centre for Education in Islamic Finance (INCEIF), Malaysia. mhamour@gmail.com

(2) Assoc. Prof., Dept. of Quran and Sunnah, International Islamic University Malaysia. eldin@iium.edu.my

\section{Contents}

1. Introduction

1.1 IFTs Variation

1.2 Dependency on Google and Google Scholar for Literature Reviews

1.3 Search Results Overlap Analysis

2. Similar Studies

3. Research Methodology

3.1 Variation Analysis

3.2 Dependency on Online Resources and the Google Test

3.3 Search Results Overlap Test

4. Summary and Findings

5. Conclusion

References

\section{Introduction}

People who are newly introduced to Islamic finance, especially if they do not speak Arabic or they are not
Muslims, have the right to think spelling variations of Islamic finance terms that have different meanings. As in the case of the term $\operatorname{Wad}^{`} a h$, which is defined in the Bank Islam glossary as safe custody, while adding an (H) after the (D) makes the term Wadī'ah. The meaning of the term also changes and becomes 'a sale based on the purchase price to the seller with a specified discount'. If two words are written differently, one justifiably should assume they have different meanings. However, this is not the case in all other variations. The spelling changes but the meaning remains the same. We should ask, does the use of these terms enhance or hinder the advancement of Islamic finance? From the author's experience of studying at the International Centre for Education in Islamic Finance (INCEIF), students who were not Muslims or did not speak Arabic found these terms confusing and challenging to grasp. 
The primary objective and motivation behind conducting any research is to advance the frontier of the BOK in that area of research. This advancement is achieved by filling in gaps, arriving at new findings, and exploring new areas of research, all of which result in expanding the boundaries of BOK. Researchers need to identify these boundaries in order to further them and this is done by carrying out literature reviews. It is essential when undertaking any research to know what has been previously published about the research topic because its research questions might have already been answered. To emphasize the point, we cite Labaree (2009) who stated that the purpose of literature reviews is to 1) identify areas of prior scholarship to prevent duplication of effort and to 2) reveal any gaps that exist in the literature. The author highlights the importance of literature reviews in determining the frontier of knowledge. This study claims that the BOK of Islamic finance is not a unified body that is being cohesively expanded, but rather is segmented and fragmented. Spelling variations might produce incomplete literature reviews negating those previously mentioned objectives and thus hindering and slowing the development of Islamic finance research.

One can safely surmise that online publications on Islamic finance could represent the majority if not the entire subject's body of knowledge. This study claims that the joint effect of the use of IFTs with their spelling variations and the dependency of users of Islamic finance literature on online resources (particularly the search engines Google and Google Scholar), led to the phenomenon coined by this study as the segmentation of BOK.

The coming together of these two factors created sub BOKs along the lines of spelling variations of an IFT. For example, this study found nine different spelling variations for the term Shariah. In figure (1) a pie chart depicts the segmentation of the BOK of Islamic finance literature along the lines of the spelling variations of the IFT Shariah. There are nine segments and sub BOKs. A researcher using only the word (Shariah) to undertake an online literature review will only cover a fraction of what is published online. This shortcoming gives rise to the chance of duplication and missing essential findings. Undertaking research and conducting literature reviews are akin to laying bricks to construct a building, each researcher needs to know where to lay his brick in the wall to raise the building higher. There are many building sites for Islamic BOK construction, represented by the segments below. Thus Islamic finance researchers cannot be sure if they are all putting bricks for the same building or not.

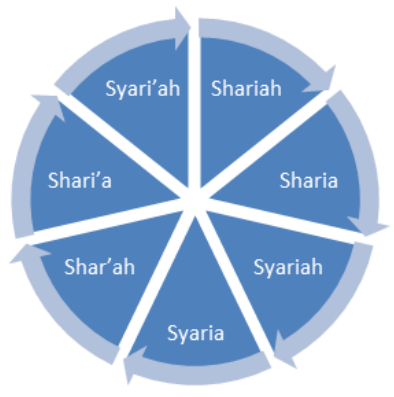

Figure 1 - BOK Segmentation

A multi-method approach was adopted to test this study's claims. Firstly, the study employs a variation analysis method to examine the presence and extent of variation among a sample of IFTs. Secondly, an online survey was administered to determine the research habits of users and producers of Islamic finance literature and their degree of dependency on Google and Google Scholar for research purposes. INCEIF students were chosen as a purposive sample to represent users and producers of Islamic finance literature. Purposive sampling is used when the sample could be logically assumed to be representative of the population. INCEIF students are all postgraduate students with diverse work experiences in the industry who could be considered as experts in the field of Islamic finance. Finally, a search results overlap analysis was carried out to test if searching for spelling variations for an IFT produces overlapping results, or there is a total separation between the results.

\subsection{IFTs Variation:}

Accompanying the rise of Islamic banking and finance was the growth of a considerable body of research on Islamic finance. A peculiar characteristic that uniquely distinguishes this literature is the use of Arabic and Islamic terms written in English letters for the purpose of naming major concepts and products. The Bank Negara glossary has more than 150 of these terms. Another feature of this terminology is the absence of a unified agreed upon spelling of these terms among the users and producers of this literature. A single IFT can 
have numerous spelling ways; this phenomenon could be partly explained by the regional difference of pronouncing and writing these terms, as is the case between the middle east, where the word Shariah is written with an (sh) and Malay speaking countries, where it is written with a (sy). Also, the word Mudarabah is uniquely written with an $(\mathrm{O})$ in Pakistan to become Modarabah. To investigate the presence and extent of spelling variations in the writing of IFTs, we conducted a variation analysis among a sample of ten IFTs. The sample was collected from the documentation and websites of ten well-known and established Islamic finance institutions (IFIs).

\subsection{Dependency on Google and Google Scholar for Literature Reviews:}

Before the advent of the internet and the digital revolution, researchers used hard resources for conducting research. This required knowledge of Library classification systems to access the right books and periodicals. Thus the use of specific search terms did not affect what literature was retrieved. However, after the internet, many if not all scholarly articles are available online and all that is required to gain access to them are a computer, internet connection and the right search keywords. The extent to which the use of the Google search engine has permeated academic culture is illustrated by a single statistic from a survey of academic authors; $72 \%$ of authors are using the Google search engine to search for scholarly articles (Friend, 2006). To ascertain the research habits of users and producers of Islamic finance literature, we surveyed INCEIF students to measure, among other things, the extent of their dependency on Google and Google Scholar for their research.

\subsection{Search Results Overlap Analysis:}

If the first and second claims are tested and accepted one can theoretically and logically conclude that there is a presence of BOK segmentation in Islamic finance literature; because of the way search engines are designed and configured. This study defines BOK segmentation as the partial return of online research results of Islamic finance topics, due to the use of a spelling variation of an IFT. This study further investigated BOK segmentation employing research results overlap analysis to confirm its existence.

\section{Similar Studies}

A literature search is an integral part of any research and publication activity. In the era of electronic databases and the explosion of scientific publication, keywords play a significant role in digging out the relevant published materials. These keywords act as "keys" to unlocking the desired scientific paper (Sharma \& Mediratta, 2002). Keywords are essential tools for information retrieval. They are usually used for the retrieval of articles based on the content of information reserved from printed and electronic resources (Kabirzadeh, Siamian, Abadi, \& Saravi, 2013). The citations mentioned emphasize the importance of keywords in research. Islamic finance is not different from any other discipline, but its research is affected by the prevalence of spelling variations in its keywords.

This paper's research topic is new, and the literature review did not reveal any work in the same area. We will give examples of original research that used search engine data similar to this paper, in the hope that this will draw the attention of the Islamic finance researchers to this new source of data. The use of search engine data in academic research is still developing and there have been studies that incorporated it into their research.

The research community has started to use publicly available internet data and especially Google search data provided by Google trends \& Insights in different areas of research. The study of Ginsberg, Mohebbi, Patel, Brammer, Smolinski \& Brilliant (2009) used search engine query data to detect influenza epidemics. Clemente \& Santillan (2019) followed the previous study and used internet search data to predict influenza outbreaks in eight South American countries. Askitas \& Zimmermann (2009) have used Google search engine data to forecast unemployment rates. Choi \& Varian (2012) have employed search engine data to forecast near-term values of economic indicators that can be used as extra pointers, and successfully leverage several US econometrics prediction models. In a different study, 
Choi \& Varian (2009) have shown Google's trends data to predict initial claims for unemployment benefits. McLaren \& Shanbhogue (2011) used data on the volume of online searches for labour and housing markets in the United Kingdom as indicators of economic activity. Chamberlin, G. (2010) investigated various search categories of Google trends data by looking at their correlation with official data on retail sales, property transactions, car registrations and foreign trips. D'Amuri (2009) tested the power of a novel indicator based on job search related web queries in predicting quarterly unemployment rates in short samples. Augmenting standard time series specifications with this indicator improves out-ofsample forecasting. Webb, G. K. (2009) proved that search data could be used as business intelligence to identify trends in US home foreclosures. The previous examples prove that search engine data could be used in new ways. For example, an Islamic bank can consider search engine results for Islamic banking products to decide where to locate new branches.

\section{Research Methodology}

The study used three different methods to test its claims. The first is variation analysis to gauge the extent of spelling variations among the study's chosen sample of terms. The second is to establish the dependency of the Islamic finance users and producers of Islamic finance literature in English on online resources, especially Google and Google scholar. The third is the search results overlap test to confirm the segmentation of the Islamic finance BOK.

The study claims that the combination of the spelling variation of IFTs and the dependency of users and producers of Islamic finance literature on online resources for research has resulted in the segmentation and fragmentation of the body of knowledge of Islamic finance literature. After examining the existence of the spelling variations of IFTs using a variation analysis, and finding evidence of the dependency of users and producers of Islamic finance on online resources, especially Google, through a survey, the study proceeds to confirm the presence of segmentation in IFT search results.

\subsection{Variation Analysis:}

Variation analysis is the process of identifying and collating all the different ways an IFT is spelled and then use one as a benchmark to establish the variation. This process was needed to prove the existence of spelling variations in the way IFTs are written in English. To accomplish this, we have conducted a variation analysis of a sample of ten IFTs from ten recognized IFIs. We searched their glossaries and website content for spelling variations of the ten terms, using the search function on their websites.

The ten chosen IFIs are International Shari'ah Research Academy for Islamic Finance (ISRA), The Islamic Banking and Finance Institute Malaysia (IBIFM), Accounting and Auditing Organization for Islamic Financial Institutions (AAOFI), the Islamic Research and Training Institute (IRTI), BNM, Institute of Islamic Banking and Insurance (IIBA), Securities Commission (SC), Islamic Financial Services Board (IFSB), Bank Al-Salam Bahrain, and Islamic Development Bank (IDB).

These are chosen for their prominence in the field of Islamic finance and/or research. The ten chosen IFTs are Shari'ah, Mudarabah, Murabahah, Wakālah, Musharaka, Istisna', Takaful, Maqasid, Ijarah and Wadi'ah, which are all key words and concepts in Islamic finance.

ISRA's spelling of the IFTs is used as a benchmark to analyse the spelling and compare variations. For this study, the word variation will signify a variation from ISRA's benchmark spelling, e.g. an IFT with five variations could be spelt in six different ways. The benchmark will be written in brackets except in headings to distinguish it from its variations.

In table (1) below, the spelling with an asterisk signifies a variation from ISRA's spelling of the IFT. In the first column, ISRA spells the word (Shariah) in two ways. First, with an $(\mathrm{H})$ at the end and a apostrophe between the (I) and the (A) before the last and an upper dash over the (I). The other spelling of the term is without a apostrophe and an upper dash. From the two spelling versions, we set (Shariah) as the benchmark for this column. Looking at the first column of the table, it seems that there are eight variations of the word (Shariah). These variations are a result of these changes 
to the term: 1) including a apostrophe between the (I) and the $(\mathrm{A}), 2)$ dropping the ending $(\mathrm{H}), 3)$ spelling it with a (Y) instead of an (SH), 4) including a apostrophe and dropping the ending $(\mathrm{H}), 5)$ including a $(\mathrm{Y})$ and apostrophe, 6) including a (Y), a apostrophe and dropping the ending $(\mathrm{H})$, and 7) including an upper dash above the (I).

In the second column, ISRA spells (Mudarabah) with an $(\mathrm{H})$ at the end of the word and this was our benchmark for comparing its variations. With two less than the first column, (Mudarabah) has six variations, as noted in the second column. The variations in the spelling of (Mudarabah) are a result of changing some letters and characters in the word, such as 1) writing it with a $(\mathrm{U})$ or an $(\mathrm{O}), 2)$ writing it with or without an end $(\mathrm{H}), 3)$ with or without a middle $(\mathrm{H})$ after the (D), as written by the securities commission, and 4) writing the middle (A) without or with an upper dash as written by the IFSB.

In the third column, ISRA spells (Murabahah) with an end in $(\mathrm{H})$ and this was adopted as the benchmark to compare the variations. In this column there are four variations of the word resulting from 1) writing it with or without the ending $(\mathrm{H}), 2$ ) writing it with a $(\mathrm{U})$ or $(\mathrm{O})$ as the second letter, 3) writing the first (A) with or without an upper dash as written by the IFSB and 4) writing it with an (O) as the second letter and dropping the ending $(\mathrm{H})$, and 5) writing it with an (O) and including the end $(\mathrm{H})$.

In column four, ISRA spells the word (Wakālah) with an upper dash in the middle (A); as in previous columns, this will be our benchmark for comparing the variations. There are four variations in the spelling of the word (Wakālah), resulting from 1) writing it without the upper dash on the middle $(\mathrm{A}), 2$ ) writing it with (AL) at the beginning of the word to become AlWakalah, 3) writing it with an (AL) at the beginning of the word but dropping the ending $(\mathrm{H})$, and 4$)$ writing it without the upper dash in the middle (A) and without the ending $(\mathrm{H})$, to become Wakala.

In column five ISRA spells (Musharakah) with a (U) and an ending $(\mathrm{H})$; analysis of the table shows it is spelt in four ways resulting from writing it 1) with or without the ending $(\mathrm{H}), 2)$ with a $(\mathrm{Y})$ instead of an $(\mathrm{SH})$, 3 ) with an upper dash over the first (A) and 4). It is evident at this stage of the sample analysis IFSB uses an upper dash over (A's), and AAOFI does not use an ending $(\mathrm{H})$.

In column six, ISRA spells the word (Istisna') with an (A) at the end and a apostrophe. Analysis of the table shows the word (Istisna') has five different variations resulting from these changes: 1) with or without a apostrophe at the end (an apostrophe?), 2) with an added (A) after the apostrophe (apostrophe?), 3 ) with an upper dash over the ending (A), 4) with an added $(\mathrm{H})$ at the end, and 5) with an added (A) and $(\mathrm{H})$ at the end of the word after the apostrophe.

In column seven, the word is (Takaful) or Islamic insurance as termed in some countries, e.g. Sudan. At this stage of the analysis, the spelling variations of the word (Takaful) is the least among our sample, and it is limited to two variations. ISRA uses two versions in their website. One is (Takaful) and the other is written with an upper dash on the second (A). For analysis, we decided to select the more common version of the two as a benchmark for comparing variations i.e. (Takaful). The variation is a result of 1) the use of an upper dash on the second (A) or not, and 2) writing it with an $(\mathrm{O})$ instead of $(\mathrm{U})$.

In column eight, ISRA spells (Ijarah) with an ending $(\mathrm{H})$ and this will set the benchmark for comparing the spelling variations. It is observed that there are two variations to ISRA's benchmark term, these are Ijara without an ending $(\mathrm{H})$ and Ijārah with an ending $(\mathrm{H})$ and an upper dash over the first (A).

In column nine, ISRA spells the word (Wadi'ah) with a apostrophe between the (I) and the (A), and this sets our benchmark for the variation analysis. It is noticeable by looking at the column that the word (Wadi'ah) has four spelling variations resulting from 1) writing it with a apostrophe ,2) writing it without a apostrophe, 3) writing it without an ending (H), 3) writing it with an (AL), no apostrophe (apostrophe?) and an ending $(\mathrm{H})$, and 4) writing it with an (AL), no apostrophe and dropping the ending $(\mathrm{H})$.

In column ten, the word Maqasid appears only in three websites of the chosen IFIs, and there is no spelling variation among them.

After the variation table analysis, one can observe that the variations range from zero to eight. The average spelling per term is (4.8), and the median is (5). 
One can also observe that the spelling variations are a result of changes in these writing variables in IFTs. They are as follows:

1. The inclusion or exclusions of the ending $(\mathrm{H})$.

2. The inclusion or exclusions of an apostrophe in the term.

3. The inclusion or exclusion of an upper dash.

4. Using a (Y) instead of (SH).

5. Replacing a (U) with an (O), e.g. Modaraba.

6. Adding a $(\mathrm{H})$ in the middle.

7. A combination of any of the above writing variables.

Table-1 Spelling Variations of IFT's

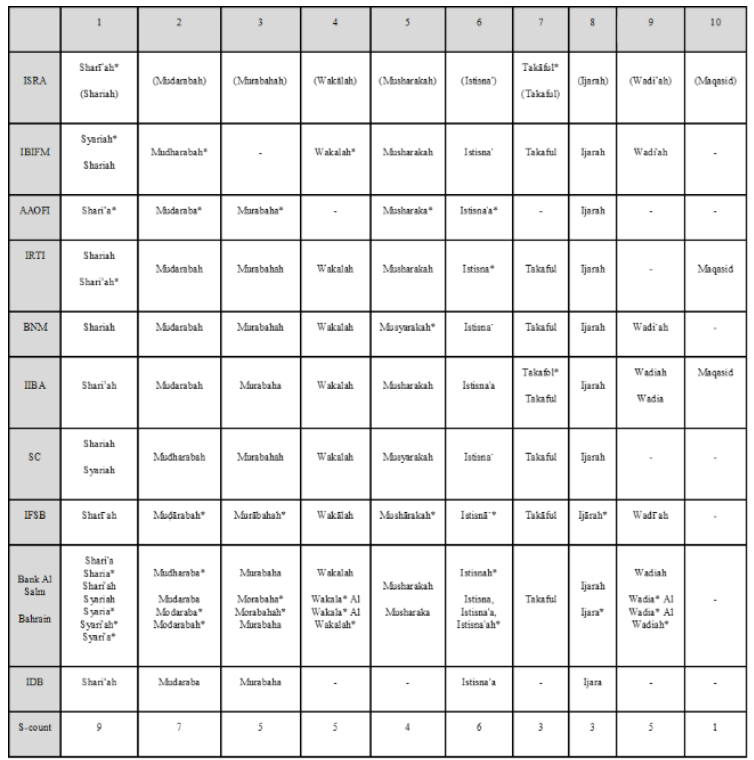

3.2 Dependency on Online Resources and the Google Test:

This study conducted a questionnaire survey to gain insights into the research habits of the users and producers of Islamic finance literature. A purposive sampling method deemed INCEIF students suitable to represent users and producers of Islamic finance literature. INCEIF students are all post graduate student who could be considered experts in the field of Islamic finance and possess various work experiences in the industry. They also come from different regions, religions, and academic backgrounds and conduct research using IFTs. The questionnaire was constructed using the Google forms online service and was launched through social media postings and email. The number of students who replied to the questionnaire was 109 out of 284, which produced an acceptable response rate of $38.4 \%$.
The students were asked, among other questions, what they mainly rely on when conducting literature reviews for research projects. The question sought to determine whether INCEIF students relied on soft or hard references for conducting their research. Responses are displayed in Table (2) below. A fifth of those who responded (20\%) indicated they rely mainly on library books and references for research, but the majority, or $(70 \%)$, of the respondents indicated a preference for online resources. This percentage is consistent with an international survey (OCLC, 2014, p.75) that reports that $79 \%$ of information searches undertaken by college students begin with a search engine. This result supports the paper's claim that today's researchers of Islamic finance rely mainly on online resources for selecting research topics and carrying out literature reviews. This finding could be easily explained by the ease of use and accessibility of the majority if not all researches that are published online.

Table-2 Questionaire Results

\begin{tabular}{|c|c|c|c|c|c|c|c|c|}
\hline $\begin{array}{l}\text { When conducting } \\
\text { Itierature reviews for } \\
\text { reseserch projects you } \\
\text { rely mainly on? }\end{array}$ & 言 & \% & $\begin{array}{l}\text { How do you conduct } \\
\text { an online iterature } \\
\text { review? }\end{array}$ & 产 & $\%$ & $\begin{array}{l}\text { What is your first } \\
\text { choice for } \\
\text { a search engine } \\
\text { when conducting } \\
\text { literature reviews } \\
\text { and other } \\
\text { assignments? }\end{array}$ & 苔 & $\%$ \\
\hline Library books & 22 & $20 \%$ & $\begin{array}{l}\text { By using search } \\
\text { engines }\end{array}$ & 24 & $22 \%$ & $\begin{array}{l}\text { Google \& Google } \\
\text { scholar }\end{array}$ & 106 & $98 \%$ \\
\hline Online resources & 76 & $70 \%$ & \begin{tabular}{c|} 
By using research \\
specialized websites \\
e.g. research gate
\end{tabular} & 12 & $11 \%$ & Yahoo & 0 & 0 \\
\hline Specialised magazines & 4 & $4 \%$ & $\begin{array}{l}\text { Combination of the } \\
\text { two previous options }\end{array}$ & 71 & $66 \%$ & Bing & 0 & 0 \\
\hline $\begin{array}{l}\text { Master's and PhO's } \\
\text { Thesis's }\end{array}$ & 5 & $5 \%$ & $\begin{array}{l}\text { Don't use online } \\
\text { resources }\end{array}$ & 1 & $1 \%$ & Ask & 2 & $2 \%$ \\
\hline Other & 2 & $2 \%$ & other & 0 & $0 \%$ & $\mathrm{AOL}$ & 0 & 0 \\
\hline
\end{tabular}

The table above shows the questions and their equivalent responses for questions one, two and three. Question two was designed to ascertain the online preference of the means of research for the paper's chosen sample. Twemty-two percent (22\%) of respondents preferred search engines to conduct online literature reviews, while $11 \%$ preferred using research specialised websites, e.g. Research Gate. The majority of respondents, or $66 \%$, indicated a preference of combine both methods to conduct online research. A common element between the two methods is the 
necessity of the use of keywords to retrieve desired articles and papers, as opposed to using directories and other means of browsing online content. Question Three highlights the dominance of the search engine Google with its research arm Google Scholar, where 98\% of respondents preferred Google and Google Scholar when conducting literature reviews.

Because of the online search feature that helps sort and present the required information in seconds, extra emphasis should be given to studying the choice of keywords that are used for the online content search. Keyword analysis could be useful to decide the names of websites, products and even academic article titles. Emerald Publishing (n.d.) advises authors to improve the chances of their article being downloaded by following some particular advice, which is to select a descriptive title that includes the most relevant keywords that demonstrate the significance of the authors' research. Another advice is to include all variants of a keyword, e.g. 'CSR' and 'Corporate Social Responsibility'. They also encourage authors to have a look at Google AdWords to find keywords that are most popular in searches. The importance of keyword selection gains more significance in Islamic finance research because of the previously determined spelling variation among most IFTs. This is significant because in Islamic finance research the choice of keywords is not just between different keywords, but also between a keyword and its spelling variations.

\subsection{Search Results Overlap Test:}

The theoretical and logical conclusions of the two previous findings are that 1) there is a dependency of users and producers of Islamic finance literature on online resources, especially on Google and Google Scholar for literature reviews, and 2) the presence of spelling variations among IFTs is reason for the segmentation of Islamic finance BOK. Following this conclusion, the study carried out a test to confirm these findings, by examining search results overlap for a range of spelling of variations for the IFT Shariah. The test criterion is that the absence of overlap indicates proof of segmentation; the alternative is the presence of search results' overlap, indicating no segmentation.

To conduct the test, we entered the nine ways of spelling Shariah into Google Scholar and collated the first twenty search results for each search. The first twenty search results represent the first two results pages at Google Scholar's default settings. Then the 180 search results for the nine searches were tabulated and examined for overlap and duplication. The examination returned zero overlaps between any of the search results, confirming the presence of segmentation in the Islamic finance body of knowledge.

\section{Summary and Findings}

In summary, this study found there are significant spelling variations among IFTs and that there is a reliance of users and producers of Islamic finance literature on Google and Google Scholar for research. Taken together, these two factors segment the BOK of Islamic finance literature. The first finding was investigated through the methodology of collecting, collating and counting the spelling variations of a sample of ten IFTs from ten different IFIs. From figure (2) below, it can be observed that the number of spellings and variations range from one spelling and zero variations for Maqasid, to the nine ways of spelling and eight variations of Shariah. The average spelling count per IFT in the sample is 4.8 spellings, and the median is 5.0 .

Figure-2 Variation Range

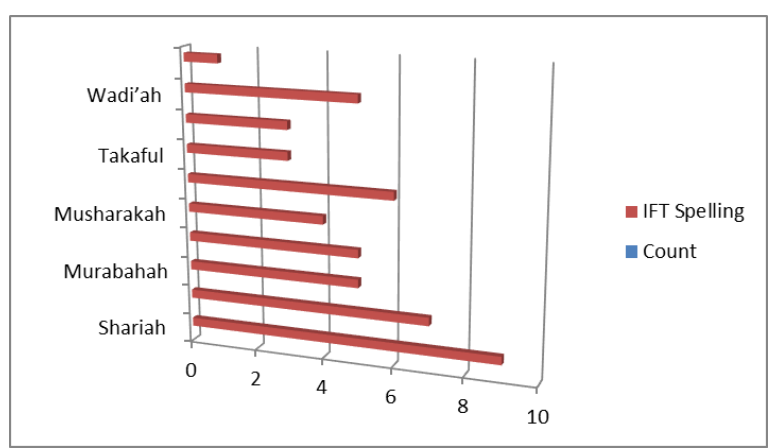

The second finding was proven by surveying a purposively selected sample of the students of INCEIF who represent users and producers of Islamic finance literature. The majority $(70 \%)$ of respondents to the questionnaire expressed a preference for online resources over other sources of research. This was in line with the study's expectations. Over half of those surveyed (66\%) reported that they combinedly use search engines and specialized research websites to undertake literature reviews. Finally, there was an overwhelming preference $(98 \%)$ for Google and 
Google Scholar over other search engines among our respondents. The consequence of the combined effect of the significance of the previous findings can only lead to the theoretical and logical inference that segmentation of the BOK of Islamic finance exists. To test and confirm the reality of segmentation, the study tested for search results overlap to prove or disprove its existence. It was found that there were no overlaps among the Google Scholar search results for the IFT Shariah and eight of its variations, confirming the presence of segmentation.

\section{Conclusion}

This study set out to draw attention to spelling variations of Islamic finance terminology and its significant impact on segmenting the BOK of Islamic finance. As a result of its historical development, which preceded the digital revolution, Islamic finance has been unintentionally segmented in its BOK. The significance of this finding might have affected and may still affect the evolvement and development of the Islamic finance BOK. This fact should sharpen the focus of stakeholders in Islamic finance on rectifying this issue through standardizing the spelling of IFTs. Until this happens, the study recommends adopting the following measures to counter the effects of segmentation. Firstly, researchers should conduct literature reviews by using all known spelling variations of an IFT. Secondly, they should include more than one spelling variation of an IFT when publishing online. An effort and drive should be initiated by Islamic finance stakeholders to unify the Islamic finance BOK by agreeing on standard spellings for IFTs written in English, so that all Islamic finance academicians and researchers are working in the same direction. Future research could investigate the reasons behind the spelling variations and why transliteration failed in unifying the spelling of Islamic finance terms.
Choi, H., \& Varian, H. (2012). Predicting the present with Google Trends. Economic Record, 88(s1), 2-9.

Choi, H., \& Varian, H. (2012). Predicting the present with Google Trends. Economic Record, 88, 2-9.

Chamberlin, G. (2010). Googling the present. Economic \& Labour Market Review, 4(12), 56.

D'Amuri, F. (2009). Predicting unemployment in short samples with internet job search query data. University Library of Munich, Germany.

Emerald Publishing. (n.d.). How to... ensure your article is highly downloaded: what you can do prior to submission. Retrieved May 24, 2019, from http://www.emeraldgrouppublishing.com/authors/guides/pr omote/optimize1.htm

Friend, F. J. (2006). Google Scholar: Potentially Good for Users of Academic Information. Journal of Electronic Publishing, 9(1).

http://doi.org/http://dx.doi.org/10.3998/3336451.0009.105

Ginsberg, J., Mohebbi, M. H., Patel, R. S., Brammer, L., Smolinski, M. S., \& Brilliant, L. (2009). Detecting influenza epidemics using search engine query data. Nature, 457(7232), 10121014 .

Kabirzadeh, A., Siamian, H., Abadi, E. B. F., \& Saravi, B. M. (2013). Survey of keyword adjustment of published articles medical subject headings in journal of Mazandaran university of medical sciences (2009-2010). Acta Informatica Medica, 21(2), 98

Labaree, R. V. (2009). Research Guides: Organizing Your Social Sciences Research Paper: 5. The Literature Review. Retrieved March 27, 2016, from http://libguides.usc.edu/writingguide/literaturereview

McLaren, N., \& Shanbhogue, R. (2011). Using internet search data as economic indicators. Bank of England Quarterly Bulletin, (2011), Q2.

Online Computer Library Center (OCLC). (2014). Tipping Point. Retrieved from https://www.oclc.org/content/dam/oclc/reports/tippingpoint/215133-tipping-point.pdf

Sharma, K., \& MEDIRATTA, P. (2002). Importance of Keywords Forretrieval of Relevant Articlesin Medline Search. Indian Journal of Pharmacology , (34), 369-371. Retrieved from http://medind.nic.in/ibi/t02/i5/ibit02i5p369.pdf

Webb, G. K. (2009). Internet search statistics as a source of business intelligence: Searches on foreclosure as an estimate of actual home foreclosures. Issues in Information Systems, 82.

\section{References}

Askitas, N., \& Zimmermann, K. F. (2009). Google econometrics and unemployment forecasting. German Council for Social and Economic Data (RatSWD) Research Notes, (41).

Clemente, L., Lu, F., \& Santillana, M. (2019). Improved Real-Time Influenza Surveillance: Using Internet Search Data in Eight Latin American Countries. JMIR public health and surveillance, 5(2), e12214. 